\title{
Usage of the VORNE 800XL production monitoring and indicator visualization system for the development of the project "Effect in a minute“
}

\author{
Jakub Liszcz ${ }^{1,{ }^{*}, \text { Klaudia Drobek }}{ }^{1}$ \\ ${ }^{1}$ AGH University of Science and Technology, Cracow, Poland
}

\begin{abstract}
Nowadays, in most of the manufacturing factories, entrepreneurs tries to "slim down" their processes. To achieve that they attempts to implement some of the "Lean Manufacturing" methodology's methods and tools with better or worst effects. Most of the failures results from the wrong approach to that subject. Leaders wants their teams to do anything faster and cheaper but too often their teammates does not exactly know why they have to do something as they do not see the goal of them. The easiest way to improve the understanding of implementation of "Lean Manufacturing" is to train whole team and arrange workshops that can educate everyone and lead the team to the common objective. One of the ideas of such an activity is the project called "Effect in a minute" created by the students from the student research group called "Management" from University of Science and Technology from Cracow (AGH- Kraków). In this article, there will be described the practical aspect of such an activity and prospect of the project's development based on the usage of production monitoring and indicator visualization system called VORNE 800XL.
\end{abstract}

\section{Introduction}

In the era of technological development and growing competition, in most branches of industry, manufacturing companies, almost every industry, struggle constantly to meet the needs and requirements of customers. Many of the techniques and methods developed on the basis of observations, research and first implementations in the world originate from the well-known Automotive concern - the Japanese TOYOTY, and specifically its Toyota Production System. The resulting Lean Management methodology has, as it turns out, a practical application in everyday life. The Student Scientific Circle "Management" of the Faculty of Mining and Geology of the AGH University of Science and Technology in Kraków (Poland), composed of students of the Faculty of Management and Production Engineering, has been infecting primary, secondary and secondary school students with the approach to life, combating waste and streamlining processes for several years. This paper presents the practical application of the Andon system from Vorne (model XL800) and the idea of using it for practical workshops conducted in schools.

\section{Lean Management and visual management}

Lean Management is the world's most popular methodology for optimizing all processes. In a nutshell, it focuses on locating and eliminating all waste (not necessarily related to cost elimination) and simplifying processes to get rid of activities that do not bring added value. TOYOTA was the protocol of this methodology. Well, it was with this company that production started to lose weight, basing on the Toyota Production System (TPS) developed in the 1950s. It assumes the use of both smaller measures, e. g. improving the comfort of work at workstations (5S), but also larger measures related to e. g. redesigning the entire production line or introducing the method of flow of one piece (One Flow Furnace). Thanks to this type of solutions, TOYOTY engineers have managed to significantly improve the production process, at the same time improving safety and comfort of work. The main components of the Lean methodology are contained in the so-called "TOYOTY House", which is presented in Figure 1.

Visual Management is one of the most important elements underlying the "lean". As the name suggests, these are activities that make use of the sense of sight, through which stimuli reach the brain the fastest, significantly affecting the speed of human reaction. These issues are presented in a symbolic way in Figure 2.

Visual management includes a wide range of measures and ways to improve the organisation of workstations, increase safety or improve communication between employees. This can be done by using specific colours, symbols or descriptions on standardised machine elements, production cells, transport routes or warehouses. A good example of visual safety features is, for example,

Corresponding author: jakub.kuba.liszcz@gmail.com 
the designated paths that pedestrians can take to separate them from transport routes, which can only be used by forklifts and other means of internal transport. An example of this type of solution is shown in Fig. 3 .

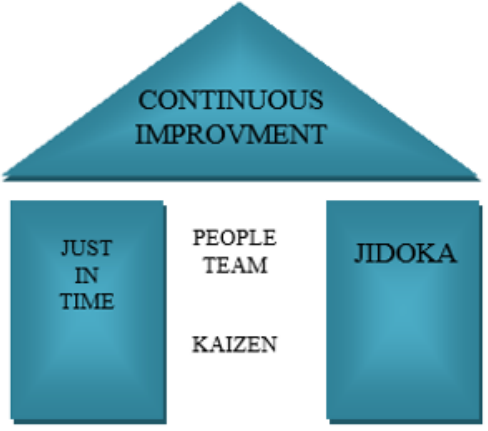

5S METHODOLOGY VISUAL MANAGEMENT

Figure 1. Simplified version of the House of TOYOTA

\section{IMPORTANCE OF VISUAL}

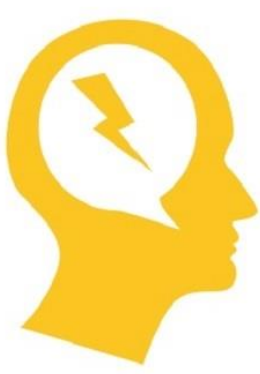

\section{0,000} People process images
60,000 times faster than text

50 milliseconds

How long it takes to form a 1st

\section{$90 \%$}

$90 \%$ of information transmitted to the brain is visual

Figure 2. Importance of visual signs for human

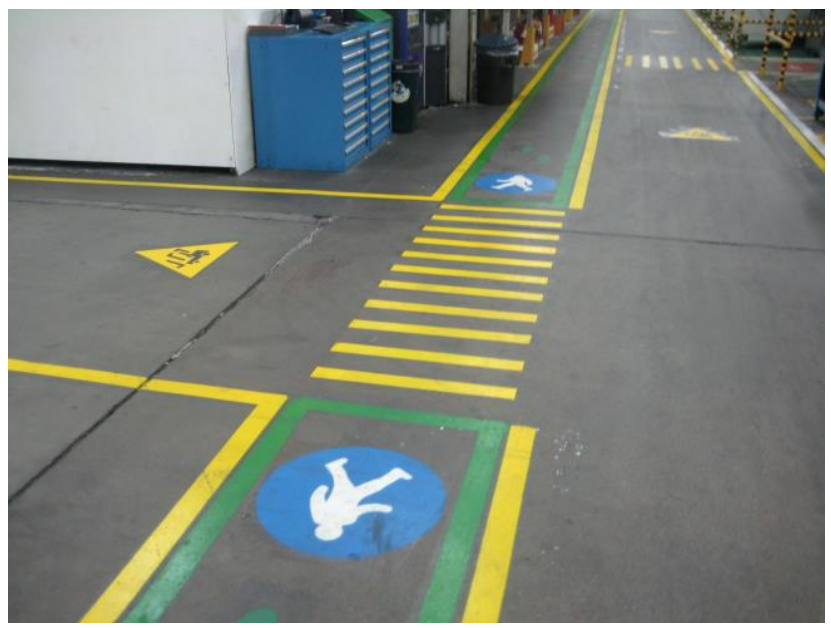

Figure 3. Example of special zone for walking and paths for forklifts

Other solutions include the use of colour identification of the elements used in production, tools or even clothing of employees, e. g. foremen or persons responsible for evacuation or first aid in case of emergency. An example of this is shown in Figure 4.

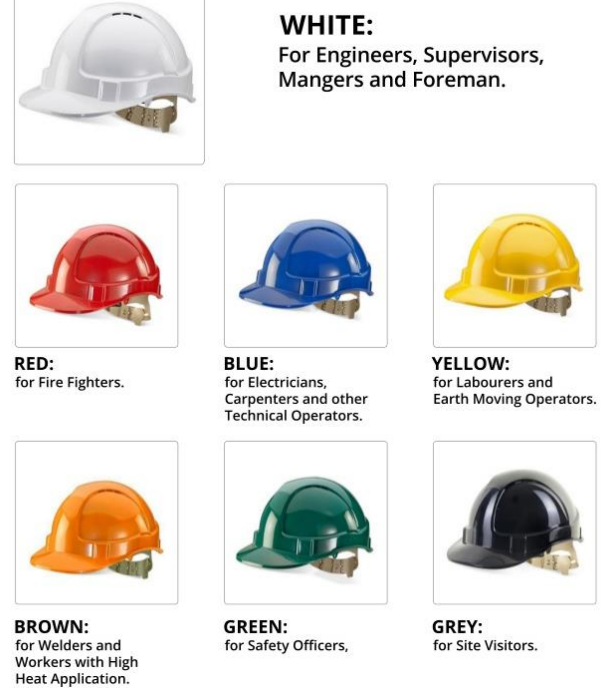

Figure 4. Example of how to identify the type of workers with the colours of protective helmets

A very important application of visual management is the use of various types of signalling, most often traffic lights, in order to control the proper functioning of individual workstations. A good example is the Andon system, which is named after Japanese and means 'light signal'. Thanks to it, it is possible to control the production process, monitor downtimes and other events and significantly speed up communication between employees. If, for example, a problem occurs on one of the starting machines and it is not possible to continue production, the Andon system will give a clear signal to maintenance personnel and operators of the following production operations.

\section{VORNE $800 \mathrm{XL}$ array as part of the andon system}

One of the tools used for visualization are boards which, as the name suggests, transmit information by means of light signals. In general, these are black, rectangular arrays containing 2 panels of LEDs, which can display freely configurable texts and shapes in several colors. Most often, however, green, yellow and red are used to present the status of a given situation, so that the recipient of information knows at first glance whether an intervention is necessary to improve, for example, the availability of machines or the quality of products. The main advantage of this type of boards is their flexibility and easy configuration. Depending on the plan of the production hall and the location of specific key locations, the number of such boards, their type and content may vary. Figure 5 shows an example of an Andon table showing 4 indicators (target number of products to be manufactured, number of pieces produced, machine performance and downtime).

The Vorne Andon System Table (model 800XL) is available in 3 variants:

$-32 \times 80$ (rows x LED columns),

$-32 \times 160$,

$-32 \times 240$. 

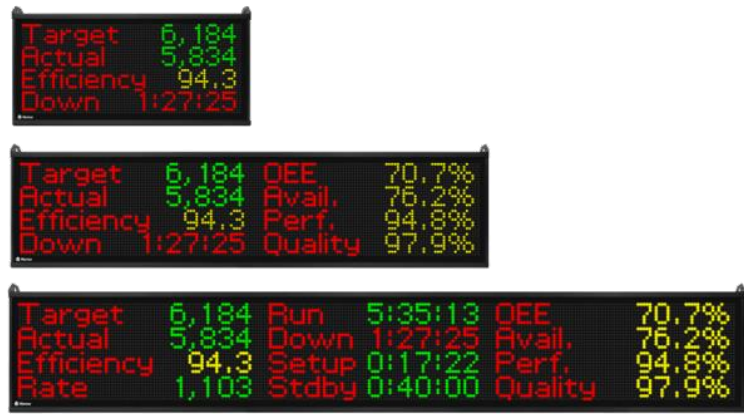

Figure 5. List of available types of tables ANDON VORNE $800 \mathrm{XL}$

As can be seen from Figure 5, depending on the variant of the array, its space presenting specific data is increased. This information is collected in real time from sensors located on the production line, e. g. counting the number of products that have left the stand. It is also possible to send signals to the board using barcode or QR readers. Therefore, by equipping their employees with such devices, they are able to record on an ongoing basis events that are not taken into account by other measurement systems.

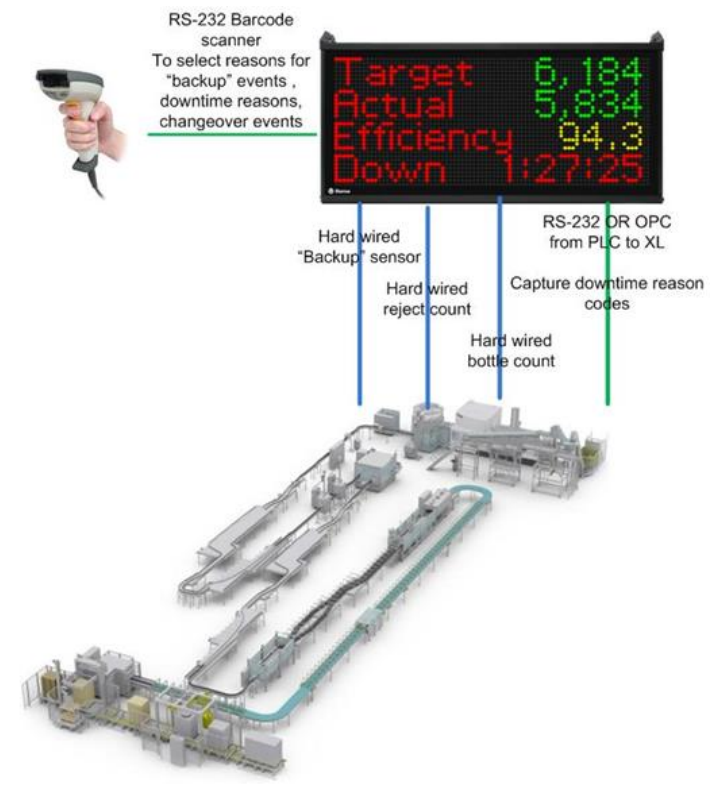

Figure 6. Diagram of data collection from production line sensors and barcode scanners

The biggest advantage of using the system with Andon arrays is dedicated software, which records signals from any connected devices and processes the data online. Thanks to this, the end user is able to control the situation in real time, because a properly configured program analyzes data in real time, recalculating and presenting even more than 100 parameters. These include data on downtime, quality and performance, as well as on machine utilisation rates (OEE and TEEP). An additional advantage of the system is the ability to display interactive dashboards, presenting the collected data in a web browser, so without the need to install special programs on different computers. You can also generate
Word $\AA$, Excel®, CSV or SQL files at any time. There is no need to prepare special reports, as they are generated automatically using the Vorne $800 \mathrm{XL}$ system. Thanks to a very simple configuration and no need to install additional applications, the system is also ideal for training in production process control and production optimization. The Vorne 800XL can therefore be used to show you how important it is to use data and make informed decisions on the basis of measurements taken from the production line, how to interpret them, and how important it is to use the data.

\section{4 "Effect in a minute" as a lean for the teenagers}

"Effect in a minute" is a project of the Student Scientific Research Group "Management", operating for over 25 years at the Faculty of Mining and Geoengineering at the AGH University of Science and Technology in Kraków. As part of this initiative, students with a passion for "lean management" are infectious with their "lean" approach by students of local primary schools, junior high schools and high schools in Poland. Seemingly difficult tools and methods associated strictly with production and science, as it turns out, are also used in everyday life improving the comfort of life through appropriate management of resources, which each of us has a limited number of. This includes time, place, energy, money. The obvious association of these terms with the management of a production company is no coincidence - just as in everyday life it also takes 24 hours, our place is limited by the surface of the production hall, flat or even desk, etc. Thus, it provides a field for reference of tools and methods such as workstation standardization, value flow analysis in order to eliminate waste, or visual management mentioned in one of the previous subsections.

Conduct of the workshops. Within the framework of the project "One minute to the effect", cycles of two workshops are conducted for specific groups, most often classes 4-6 of primary schools, 1-3 of middle schools and high schools, tailored to the age of participants. During the first meeting, students will learn the basics of Lean methodology, the main pillars of the TOYOTY house and the basics of standardization based on everyday activities (desk organisation, room management and time at home). Students who conduct the workshops also familiarize teenagers with a well-known tool, also derived from the Lean methodology, called 5S (Selection, Systematics, Cleaning, Standardization, Self-Check from the first letters of the next steps).

The second meeting is based on a simulation of the production process. The participants take over the roles of the company's director, logistics manager, warehouse manager, quality controller and production staff gathered in various production cells. Together, they form a joint venture to meet the requirements of the customer (the person running the workshop), which are the specific quantities of finished products. Depending on the age of the students, the level of difficulty of the products is 
chosen. Figure 7 shows examples of variants produced in workshop 2 "One minute to the effect":

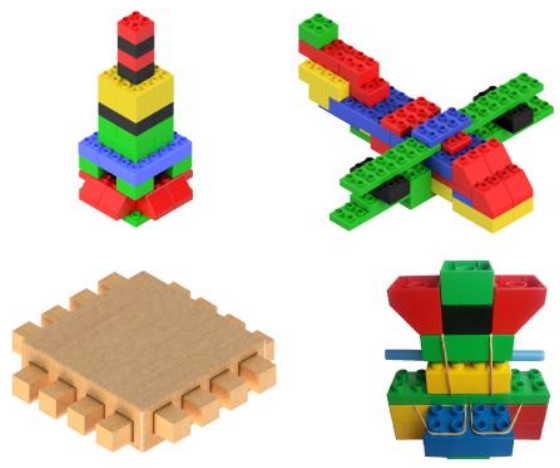

Figure 7. Development of products that are items of production in the educational project "Effect in a minute"

In the second part of the workshop, participants face the challenge of producing a number of different product variants and delivering them to the customer at the right time. In case of any quality errors, these products are not accepted by the recipient and the "company" created by the participants records losses. As the project is designed to demonstrate the importance of a "continuous improvement" approach, between each simulation the pupils jointly analyse the results achieved in a given production cycle and take the next steps to improve their performance. In this way, the theoretical issues raised during the first workshop can be put into practice in order to improve the participants' performance.

Evaluation of the project. In the newest, already fourth edition of the project, participants of the workshops will take part in a simulation of the process of production of cars from LEGO blocks, developed in relation to previous editions. Despite the relatively simple construction and much smaller size of the products, than in the case of the previous buildings, the new formula will allow for much more. The main advantage is the possibility to replace simulations, during which up to six pieces were produced with much larger "production orders" assuming that participants will face more mass production. Based on experience from real factories in various industries, mass production is more susceptible to various tools of the Lean Management methodology. Therefore, the amount of information passed on by the instructors will increase, so that the workshops with LEGO cars will be addressed to the oldest of all the participants of the project.
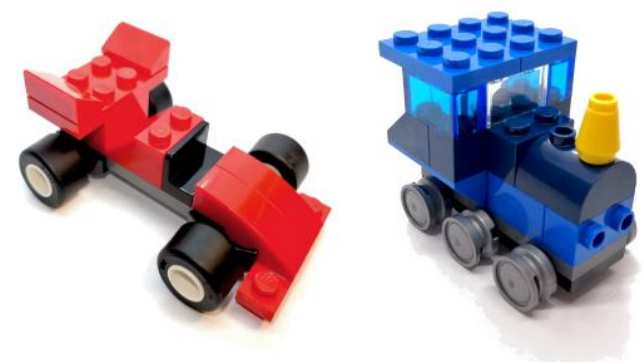

Figure 8. Evaluation of the products of "Effect in a minute" product.

\section{Summary}

Taking into account all the advantages of the Andon Vorne 800XL system and its easy installation anywhere, it is planned to use it to diversify the workshops as part of the project of the Student Scientific Circle "Management". Equipping individual production cells with barcode scanners will enable current analysis of the results of the team and the effectiveness of implemented improvements. This will take the "One Minute to Effect" workshop to a higher level, while showing high school dents how important the data are not only in relation to the production cycle, but also in the life around us. Thanks to them, we can draw the right conclusions and make our actions more efficient, effective and thus the daily duties or new undertakings will be less stressful and will bring a lot of positive experience in return.

\section{References}

1. A. Byrne: Jak zrewolucjonizować firmę dzięki Lean management (Lean Enterprise Institute Polska, Poland 2018).

2. E. Richardson, T. Richardson: LeanSpeak. The Productivity Business Improvement Dictionary (Lean Enterprise Institute Polska, Poland 2018).

3. M. A. Junewick, in: Diffusion Processes in Advanced Technological Materials (New York: Productivity Press, 2002).

4. J. Nicholas, Lean Production for Competitve Advantage (CRC Press, New York, 2011).

5. J. P. Womack, Maszyna, która zmieniła świat (ProdPress.com, 1990) 